\title{
Simulation of Ballast Water Dispersion in the Gulf of Tonkin and Offshore Waters of Hai Phong Port, Vietnam
}

\author{
Hoang Mai Le ${ }^{1, *}$, Cong Minh Nguyen ${ }^{1}$, Thanh $\mathrm{Ca} \mathrm{Vu}^{1}$, Thanh Thuy Tran ${ }^{1}$, Van Dien Nguyen ${ }^{1}$, and Huy Ram Dang ${ }^{1}$
}

'Vietnam Administration of Seas and Islands, 83 Nguyen Chi Thanh, Ha Noi, Viet Nam

*Corresponding author: lehoangmai82@gmail.com

\section{KEYWORDS}

Dispersal

Hydrodynamic modelling

MIKE21

Monsoon

Surface current

\begin{abstract}
Transfer of invasive alien organisms and their negative impacts have been recorded around the world. It is estimated that approximately 7,000 species of marine creatures are silently moved around the world by ballast water every hour. Recently, discharge of ballast water in the coastal area has become a serious concern. The movement of discharged ballast water and accompanying alien organisms largely depends on the prevailing hydrodynamics of the receiving water body. Dynamics simulation models for marine environment provide sound prediction of dispersion of ballast water. The study was undertaken in the seas of the Gulf of Tonkin and in the offshore area of Hai Phong Port using the MIKE 21 model - a two-dimensional hydrodynamics model. The yearly-mean wind field was used in the model to generate the circulation. Ballast water discharged to the three sites in the study area was simulated by using dispersal-advection model. The outputs showed that ballast water discharged near the coast tends to move along the coastline. Ballast water discharged at 200 NM seaward from the coast is still able to influence the coastal zone of Vietnam.
\end{abstract}

(c) The Author(s) 2018. This article is distributed under a Creative Commons Attribution-ShareAlike 4.0 International license.

\section{INTRODUCTION}

The discharge of ballast water and accompanying alien organisms imposes threats on native marine organisms. Studies on impacts of alien species introduced via ballast water on native organisms have been undertaken in some countries. However, impacts of shipping and ballast water on native environment have been limited. This study assesses dispersion of ballast water driven by local hydrodynamics. This helps to determine appropriate places for discharging ballast water and areas at risk of ballast water discharge in the study site.

The Gulf of Tonkin (hereafter the Gulf; Figure 1) is located to the west of the eastern Vietnamese waters (East Seas) in the Pacific Ocean, spreading from $105^{\circ} 36^{\prime} \mathrm{E}$ to $109^{\circ} 55^{\prime} \mathrm{E}$ and from $17^{\circ} \mathrm{N}$ to $2^{\circ} \mathrm{N}$. The area of the Gulf is approximately $127,600 \mathrm{~km}^{2}$. The perimeter of the Gulf is 314 km (Figure 1). The Gulf has two entrances, i.e., Quynh Chau straits, 19 NM at width, locating in between Loi Chau Peninsula and Hai Nan Island; and the main entrance, 112 NM at width, spreading from Con Co Island (Vietnam) to Oanh $\mathrm{Ca}$ (Hai Nan island, China).

The Gulf of Tonkin is fairly shallow. The average depth is in the region of 40 to $50 \mathrm{~m}$, and the maximum depth is about $100 \mathrm{~m}$. About $60 \%$ of the area of the Gulf is less than $30 \mathrm{~m}$ in depth (Figure 1). The seabed is fairly flat, although it is gently sloping towards the center and rises sharply towards Hai Nan Island. The slope of the northern and western parts of the seabed is less steep than that of the eastern and southern parts (Figure 1). Because of the shallow nature of the Gulf, circulation and water bodies within it possess distinctive characteristics related to unique natural conditions of the Gulf. Circulation is caused mostly by prevailing winds on the sea surface that interact closely with the East Seas. Exchange of water at the Gulf entrance also brings about changes in the diversity of distribution and fluctuation of seasonal circulation in the Gulf.

Hai Phong is the second largest international port of Vietnam, located in Hai Phong City. Hai Phong Port is able to handle vessels of 10 to 20 thousand tons capacity. In the

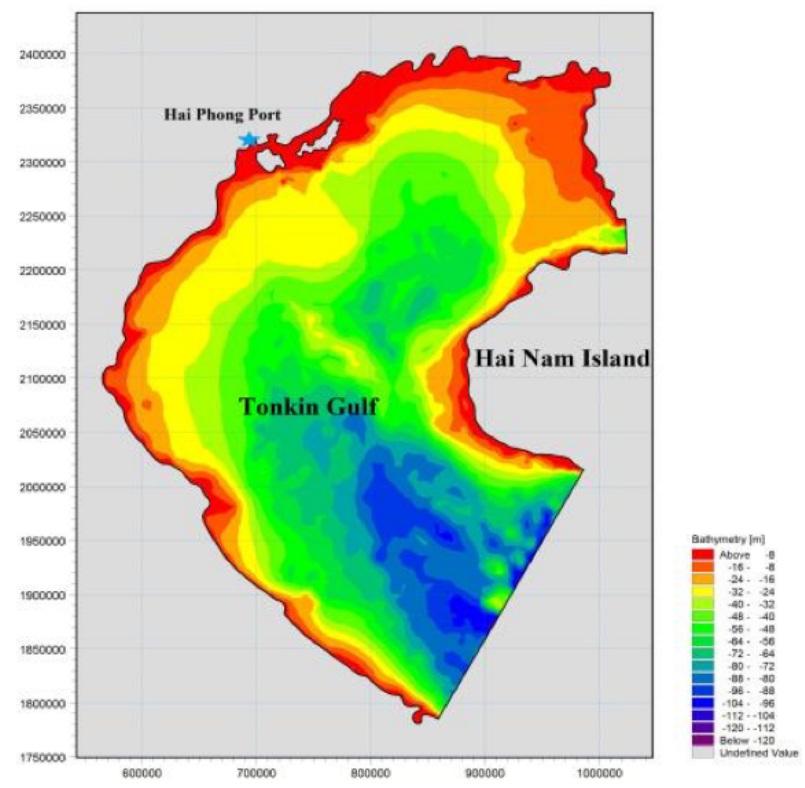

Figure 1. Bathymetry and seabed morphology in the Gulf of Tonkin off the Vietnam coast. 


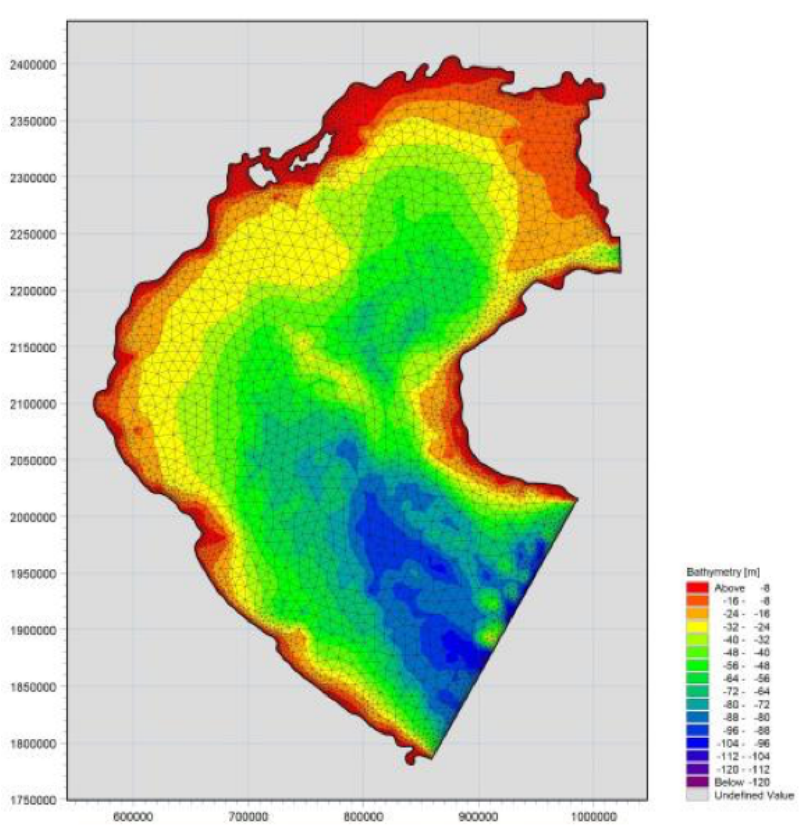

Figure 2. Model domain and mesh used in the study.

period 2005 to 2009, the port received almost 30 million tons of goods. Vessels from the region as well as from other countries such as England, France, Italy, Japan, China, India, and ASEAN countries have called at Hai Phong. Hai Phong Port is located close to two internationally recognized Biosphere Reserves, i.e., Cat Ba Biosphere Reserve and Red River Delta Biosphere Reserve. Both have high biodiversity value and are at risk of invasive alien species.

Some studies were undertaken in the past to investigate currents in the Gulf of Tonkin based on threedimensional hydro-thermodynamics and wind-forces. Geostrophic current was studied based on temperature and saline fields (Xu et al. 1982; Siripong 1984; Uu and Brankart 1997). Wind-forced currents were investigated by Chao et al. (1995, 1996) and Huong (2013). However, studies on simulation of transportation of wastewater or
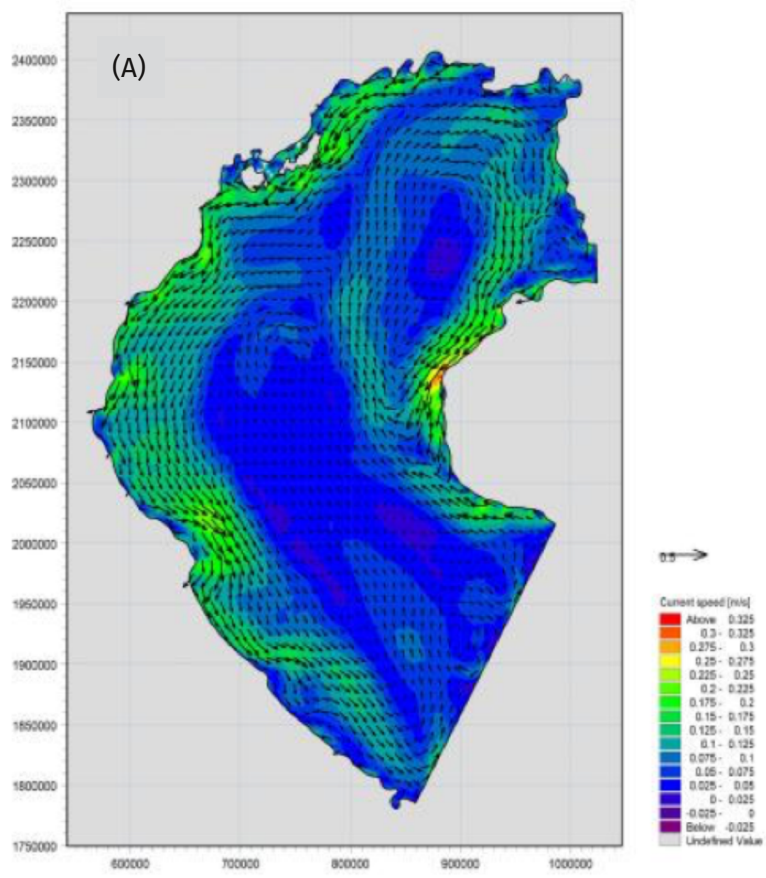

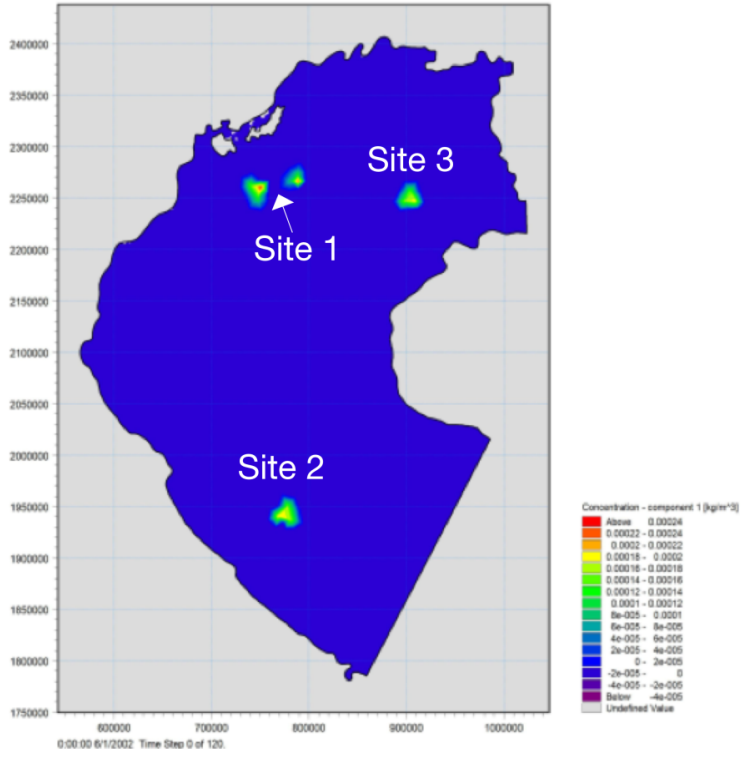

Figure 3. Simulation zone and ballast water discharge points used in the study. Site 1 comprised two points, whilst Sites 2 and 3 comprised one point each.

ballast water (e.g., Han et al. 2008; Bailey et al. 2011) in the region have been rarely reported.

\section{MATERIALS AND METHODS}

MIKE21 is a commonly used software package for twodimensional simulation of flow, wave, sediment transportation and environmental processes.

Depth data were obtained from bathymetric charts provided by Vietnam High Command of Navy. Data on wind field were collected in June and December, representing Northeast and Southwest monsoon seasons in the seas of the Gulf of Tonkin. Simulation of hydrodynamics and dispersion of ballast water were calculated for 30 days after discharge. The model domain and mesh are shown in Figure 2.

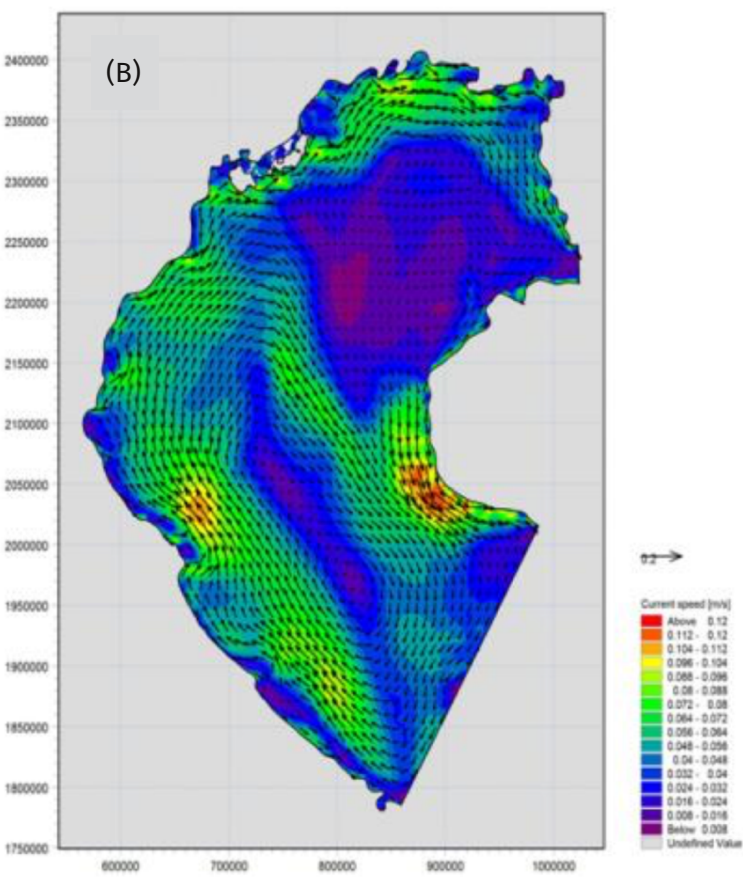

Figure 4. Current speeds in the Gulf of Tonkin during the Northeast and Southwest Monsoons. (A) Northeast Monsoon; (B) Southwest Monsoon. 

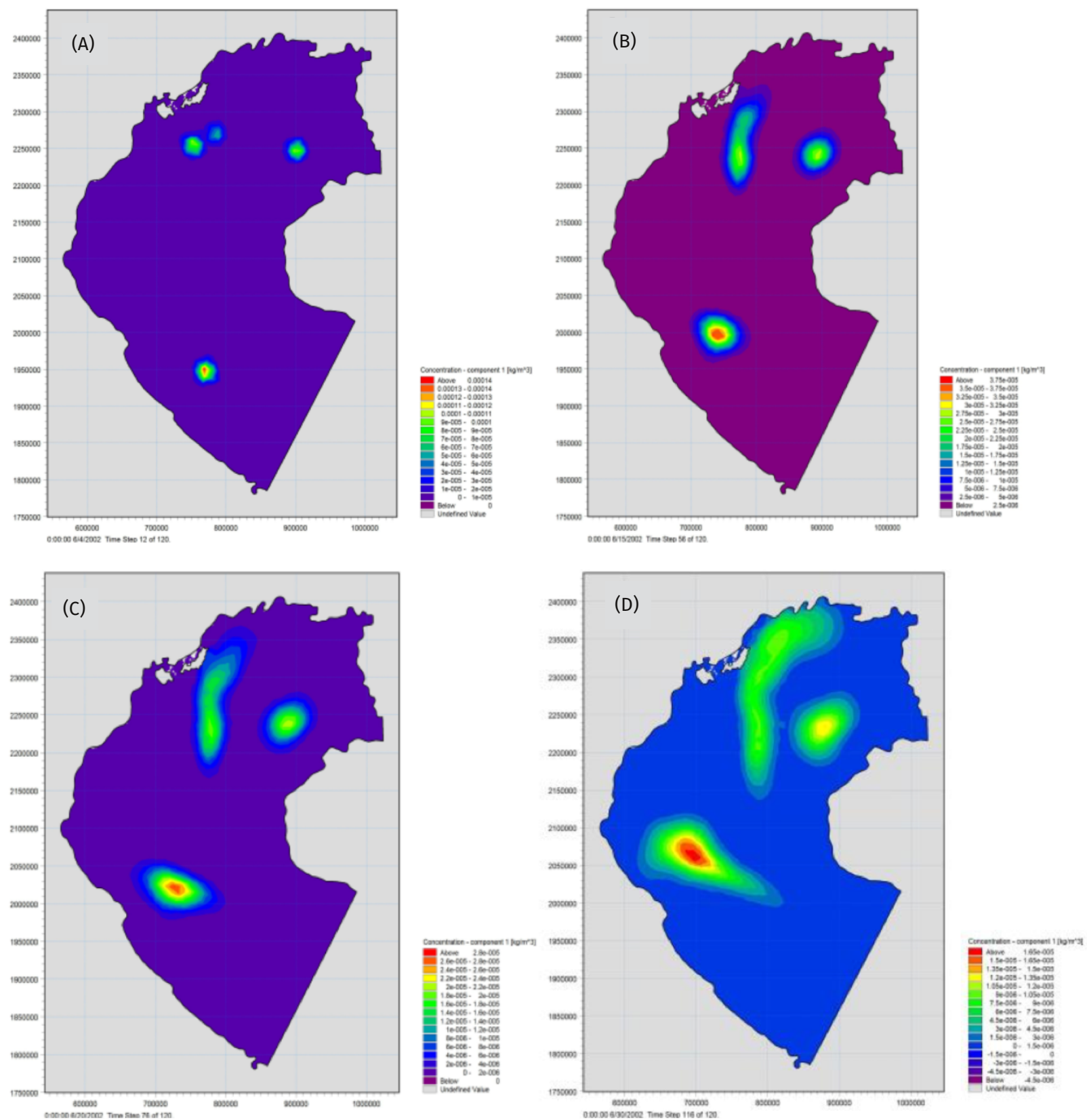

Figure 5. Results of simulation of the dispersion pattern of ballast water released at three points in the Gulf of Tonkin during the Southwest Monsoon, (A) after 3 days; (B) after 15 days; (C) after 20 days; (D) after 30 days.

The model was adjusted and validated by existing data in the study site. Once the model was set up, four ballast water discharge sites were designated: the first site comprises two points at $30 \mathrm{NM}$ offshore of Hai Phong Port; the second site (with one point) was in the Southern part of the Gulf on the maritime route from the South, through the Gulf's entrance, to the Hai Phong Port at 180 NM long; and the last site, also with one point, was on the maritime route from Quynh Chau Straits to Hai Phong Port at 115 NM (Figure 3). MIKE21TR was applied to investigate the dispersion of ballast water at these four points. Assumed volume of ballast water was 1000 tons and assumed concentration of materials was $10^{-3} \mathrm{mg} / \mathrm{L}$.

\section{RESULTS AND DISCUSSION}

Results of the hydrodynamics simulation in December and June representing two seasons, i.e., Northeast and Southwest monsoon seasons are shown in Figure 4. The major current in the Northeast monsoon season (December) is known as the western coastal current and tends to be southward in direction. In the northeastern part of the Gulf, there is an anticyclonic circulation that brings about a southward current running along the western coast of the Hai Nan Island. The current speed in western coast of the Gulf of Tonkin and western coast of Hai Nan island is approximately $0.11-0.17 \mathrm{~m} / \mathrm{s}$. The current speed in the central region of the Gulf is lower, approximately $0.03-0.07 \mathrm{~m} / \mathrm{s}$.

The major current in the Southwest monsoon season is western coastal current which tends to be northward in direction, bringing about eddies in the central and southern part of the Gulf of Tonkin. There is also an anticyclonic eddy in the northern part of the Gulf. The highest current speed is observed in the southwestern coast of the Gulf of Tonkin and the southwestern coast of Hai Nam island at $0.14-0.16 \mathrm{~m} / \mathrm{s}$. The mean current speed in the other area is about $0.04-0.08 \mathrm{~m} / \mathrm{s}$. The current 

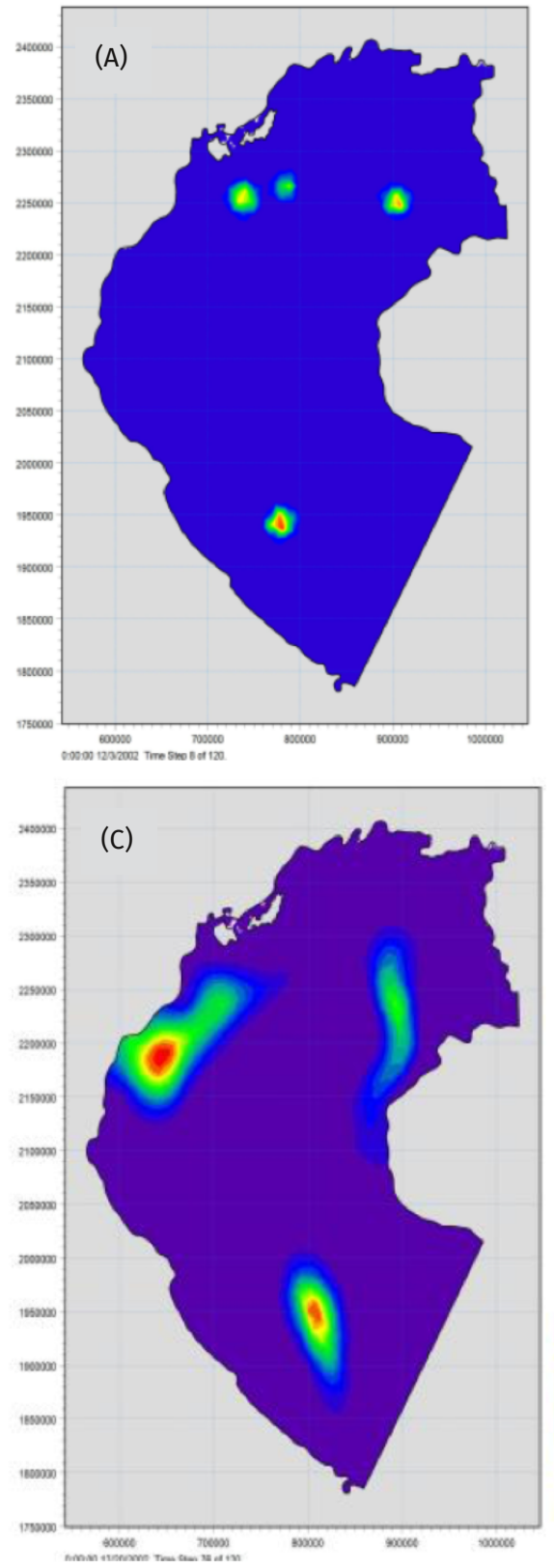
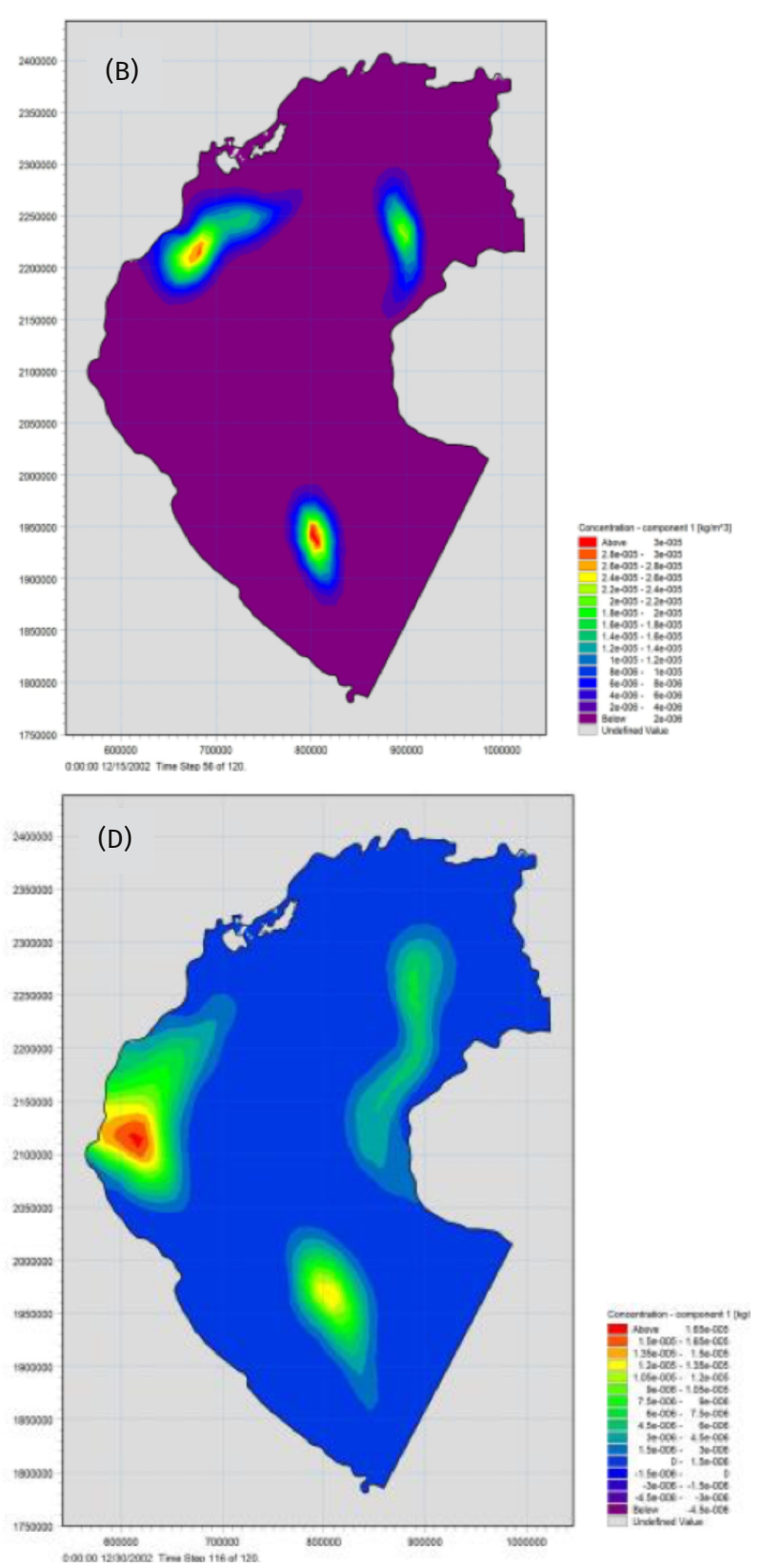

Figure 6. Results of simulation of the dispersion pattern of ballast water released at three points in the Gulf of Tonkin during the Northeast Monsoon, (A) after 3 days; (B) after 15 days; (C) after 20 days; (D) after 30 days.

speed is lowest in the central of the eddy and is about $0.02-0.035 \mathrm{~m} / \mathrm{s}$. Simulation results of ballast water dispersion over time in the three study sites are shown in Figures 5 and 6.

\subsection{Southwest monsoon season}

Results of the simulation of dispersion of ballast water after 30 days following the discharge showed that in the southwest monsoon season, ballast water transport to the north of the Gulf of Tonkin and the coast of Vietnam was not affected. At the second study site, due to the effect of the current, the ballast water streak spread toward the northeast as well as southwestward in the Gulf. After 30 days, the streak ran southeastwards and approached the coastal waters of Vietnam. By this time, the streak became largest in size and dilution ratio was highest. Concentration of materials was reduced by 15-17 times. At the third study site, the dispersion direction was northeast and southwestward, and generally adhered close to the coast of Vietnam. The area of the streak became larger, but the concentration of materials was still higher than that of the other two study sites $\left(1.5-1.6 .10^{-5} \mathrm{~kg} / \mathrm{m}^{3}\right)$ and reduced by $10-12$ fold.

\subsection{Northeast monsoon season}

Results of the simulation of ballast water dispersion showed that the area of dispersion in the northeast monsoon season is larger than that during the southwest monsoon season. At the first study site, the effect of ballast water on the seas of Vietnam was not observed after 30 days since the discharge. Because of effect caused by the current, the ballast water streak spread toward northwest and southeastward in the first 7- 20 days and then redirected to north - southward. After 30 days, the streak went northwards and part of it approached Hai Nan Island.

At the second study site, due to effect caused by the current, the ballast water streak spread northwest southeastward and then went up north to the central region of the Gulf of Tonkin after 30 days since the discharge.

The direction of dispersal of the ballast water streak at the third study site is northeast - southwestern along 
the coast of Vietnam across the provinces of Nam Dinh Ninh Binh - Thanh Hoa where the Red River Biosphere Reserve is located. The dispersion area was larger than that modeled for the Southwest Monsoon season. The concentration of material in the central region of the cyclone was also higher and reached $1.5-1.65 .10^{-5} \mathrm{~kg} / \mathrm{m}^{3}$ corresponding to a lower dilution ratio.

\section{CONCLUSIONS}

The results of the simulation have provided insight into the ballast water transportation in the Gulf of Tonkin and the offshore area of Hai Phong port. Our simulation results showed that:

1. Coastal dispersion of ballast water always goes along the coast and does not come into the centre of the Gulf. Dispersion area of the ballast water in the northeast monsoon season is larger than that in the southwest monsoon season.

2. Ballast water transports away from the point of discharge. However, direction, dispersion extent, and dilution ratio vary between northeast and southwest monsoon seasons.

3. Dispersion extent of ballast water discharged in the discharging point close to the Hai Phong Port is largest and possibly imposes threats on coastal estuarine ecosystems of Vietnam. Particularly, in northeast monsoon season, it can threaten the Red River Delta Biosphere Reserves.

As data on invasive alien organisms were not incorporated in the simulation, it is not possible to give any comment on their transportation and behaviour.

\section{RECOMMENDATIONS}

1. Data on organisms in ballast water transported to and from Vietnam are limited, so the simulation may not be entirely accurate and may result in static reality. Therefore, investigations concerning the contents of ballast water in vessels should continue to gather more information, so that data synchronization can be effected across space and time. Molecular sequence data on organisms in ballast water may also be necessary.

2. Further studies are needed to build realistic scenarios based on the spread of ballast water in sensitive locations, so as to provide pertinent warnings and advice on the marine environment in the light of maritime trade in Vietnam as well as across ASEAN countries and India.

\section{ACKNOWLEDGEMENTS}

The study was funded by the ASEAN- India cooperation project "Extent of transfer of alien invasive organisms in south/southeast Asia region by shipping". The authors acknowledge the support of Drs. K.S. Tan and A.C. Anil (ASEAN and Indian coordinators of the project respectively). We are grateful to Professor Dinh Van Uu (Hanoi National University) for his contribution to the paper review process.

\section{REFERENCES}

Bailey S, Wells MG, Ruddick B. 2011. The dilution and dispersion of ballast water discharged into Goderich Harbor. Marine Pollution Bulletin 62(6):1288-1296.

Chao SY, Shaw PT, Wang J. 1995. Wind relaxation as possible cause of the South China Sea warm current. Journal of Oceanography 51:111-132.

Chao SY, Shaw PT, Wu S. 1996. El Niño modulation of the South China Sea circulation. Progress in Oceanography 38:51-93.

Han G, McKenzie C, He M. 2008. Dispersive characteristics of ballast water exchanges off Newfoundland: a model-based study. Estuarine and Coastal Modeling 2007:999-1018.

Huong HT. 2013. Gulf of Tonkin circulation structure fluctuation. Science Journal of Hanoi National University, Science and Technology 29(1S):80-88.

Siripong A. 1984. Dynamics of thermal structure in the upper layer and surface circulation in the South China Sea. VNIIGMI-MCD 4:101

Uu DV. 2013. Characteristics of the hydrodynamic and the environment at the Bach Dang estuary. Science Journal of Hanoi National University, Science and Technology 29(1S):196-200.

Uu DV, Brankart JM. 1997. Seasonal variation of temperature and salinity fields and water masses in the Bien Dong (South China) Sea. Mathematical and Computer Modelling 26:97-113.

Xu XZ, Qiu Z, Chen HC.1982. The general descriptions of the horizontal circulation in the South China Sea. Paper read at the 1980 Symposium on Hydrometeology of the Chinese Society of Oceanology and Limnology, Beijing. 
